\title{
Comunicación y propaganda durante la dictadura de Primo de Rivera (1923-1930)
}

\author{
Lluís Costa FernáNDEZ \\ Universidad de Girona \\ lluis.costa@udg.edu
}

\begin{abstract}
Resumen
La hipótesis de trabajo que intentamos desarrollar en el presente artículo parte de una idea central: el proyecto político de Primo de Rivera se fundamentó, sin éxito, en el desarrollo de una intensa labor comunicativa-propagandística. En una época en que la prensa era casi el único medio de comunicación de masas, Primo de Rivera interpreta su función como un verdadero cuarto poder. La manipulación comunicativa la ejerce a través de la censura y de las notas de obligada inserción, las cuales acentuaban el tono populista del régimen. La aplicación de este control presentará muchas contradicciones, aunque en algunos aspectos servirá de modelo a la dictadura franquista.
\end{abstract}

Palabras clave: prensa, censura, dictadura, propaganda, Primo de Rivera, franquismo.

\section{Communication and advertising during the dictatorship of Primo de Rivera} (1923-1930)

\begin{abstract}
The working hypothesis that is developed in this article is based on a central idea: the political project of General Miguel Primo de Rivera (1923-1930) was based, unsuccessfully, in the development of an intensive work of propaganda. At a time when the press was almost the only means of mass communication, Primo played his role as a true fourth estate. Communicative manipulation was exercised through censorship and notes of required insertion, which accentuated the populist tone of the regime. The application of this control had many contradictions but in some ways it was used as a model to the Franco dictatorship.
\end{abstract}

Key Words: press, censorship, dictatorship, propaganda, Primo de Rivera, Francoism.

\section{Referencia normalizada:}

Costa Fernández, L. (2013) Comunicación y propaganda durante la dictadura de Primo de Rivera (19231930) Historia y Comunicación Social. Vol. 18. Nº Especial Diciembre. Págs. 385-396

Sumario: 1. Introducción. 2. Metodología. 3. La censura: instrumento de coacción y control. 4. La imagen de los despropósitos. 5. Conclusiones. 6. Referencias bibliográficas. 


\section{Introducción}

La dictadura del general Miguel Primo de Rivera (1923-1930) se inicia en el periodo histórico previo al pleno desarrollo del fascismo italiano, que comenzó en los años 1925-1926, y del nacionalsindicalismo alemán de los años 1933-1934. A diferencia de los regímenes fascistas que disponían de una política clara, explícita, integral y movilizadora, los regímenes militares-corporativos -como el de Primo de Rivera- sólo presentaban una cierta mentalidad política común, basada en el pensamiento militar-burocrático y en la corriente de pensamiento orgánico-estatista. El régimen desarrolló una intensa labor propagandística, capaz de movilizar y organizar los hombres afines a la Dictadura. De hecho, una parte importante del destinatario del mensaje de Primo de Rivera era un segmento de población apática que, a criterio de los ideólogos de la dictadura necesitaba una profunda "propaganda oral y escrita, metódica, organizada, continúa, teniendo en cuenta que para la colosal tarea de salvar a un gran pueblo no basta la fría razón: hay que despertar y encender en él la llama de la pasión"1.

La imperfecta reglamentación de la prensa que el Directorio heredó de la Restauración, y que con una mínima capacidad y voluntad política hubiera podido mejorar, no experimenta ningún avance a lo largo de los siete años de Dictadura. Primo de Rivera se obstina en apropiarse de la prensa, y lo pretende hacer sin diseñar un sistema de prensa debidamente estructurado, adaptando mecanismos muy primarios, sustentados -y esto es importante remarcarlo- en la improvisación, con el objetivo de obtener frutos absolutamente inmediatos. Es decir, el régimen intenta reglamentar la prensa por la vía del control.

La hipótesis de trabajo que intentamos desarrollar en el presente artículo parte de una idea central: el proyecto político de Primo de Rivera se fundamentó, sin éxito, en el desarrollo de una intensa labor comunicativa-propagandística que tenía como objetivo transmitir una buena imagen del régimen e inculcar ideología. En una época que la prensa era casi el único medio de comunicación de masas, Primo de Rivera interpreta su función como un verdadero cuarto poder. El militar había interiorizado la idea según la cual "la información periodística juega un papel clave en la estructuración de la percepción ciudadana y en la formación de la opinión pública"2. La manipulación comunicativa la ejerce a través de la censura y de las notas de obligada inserción, las cuales acentuaban el tono populista del régimen, caracterizado por su contacto directo -y casi diario- con la población. La coerción era una indiscutible medida del poder para controlar a la población, pero el régimen también se preocupaba por modelar el pensamiento de sus súbditos, para que asimilara unas determinadas ideas. Como escribe Xavier Rull: "Si pensamiento y lenguaje están íntimamente unidos, una manera de condicionar el pensamiento puede ser conformar un determi-

1 TARDUCHY (1929): 309 y 311-312.

2 CASERO (2009): 364. 
nado lenguaje. De esta manera, el lenguaje puede ser una herramienta para hacer que los demás interpreten la realidad tal como tú quieres que la interpreten"3.

La aplicación de este control presentará muchas contradicciones, aunque en algunos aspectos servirá de modelo a la dictadura franquista. Primo de Rivera interpretó la función de la prensa como un verdadero cuarto poder. Su primer objetivo era controlarla a través de la censura.

Durante muchos años hemos repetido, con insistencia, que el período de la dictadura de Primo de Rivera había dispuesto de muy poco interés por parte de la historiografía. ${ }^{4}$ A las investigaciones ya tradicionales de autores como Ben-Ami (1983), Gómez-Navarro (1991 y 2003), Roig Rosich (1992), González Calbet (1987) o González Calleja (2005), cabe añadir las interpretaciones del período fundamentadas en puntos de vista más locales como las obras de Pérez Romero (1983), Garrido Martín (1997), Fuentes Langas (1998), Gatica Cote (2004), Jiménez Martínez (2003), entre otros. La óptica local ha permitido disponer de diversos partes de un mosaico que cobra más sentido a partir de estos nuevos conocimientos derivados de investigaciones centradas en territorios específicos de la geografía española. El esfuerzo por construir una historia general a partir de visiones particulares, resulta, sin duda, una asignatura pendiente en el ámbito historiográfico. Podríamos definir el estado de la cuestión como un hipotético proyecto con materiales disponibles para su realización. Las referencias comparativas con situaciones dictatoriales europeas se reducen al caso del fascismo italiano. En el ámbito concreto de la prensa continua resultando absolutamente imprescindible los conocimientos e informaciones aportadas por la gran obra de Celedonio de la Iglesia.

\section{Metodología}

Sustentar en gran medida la metodología de trabajo en el análisis hemerográfico comporta algunos riesgos, ya que existe una cierta tendencia, en algunos sectores historiográficos, a poner en duda algunos valores consustanciales del productor del documento, o sea del periodista. Cabe recordar que el pensador Jean Le Rond D'Alembert afirmaba, ya en el siglo XVIII y de acuerdo con el punto de vista de los ilustrados, que "no hay nada que aprender en un diario, ya que el periodista es amigo o enemigo de quien habla, y esta opinión, pues, no me parece interesante conocer". En esta misma línea, Bermúdez de Castro, publicaba, el 25 de julio de 1841, un artículo en el periódico madrileño El Iris donde sostenía que «si las publicaciones periódicas son un tesoro para la posterioridad, son también el mayor de los peligros para la investigación contemporánea [...]. Los periódicos están destinados á representar todas las pasiones, todos los intereses pasajeros de un país".

3 RULL, Xavier, "Política i manipulació del llenguatge", Comunicació. Revista de recerca i anàlisi, núm. 27, Societat Catalana de Comunicació, Barcelona, 2010, p. 107.

4 Fernando Martínez López lo recordaba en el prólogo de la obra de MARTíNEZ GÓMEZ (2007): 11. 
El análisis de las estrategias comunicativas de Primo de Rivera implica la absoluta necesidad de aplicar una metodología de trabajo basada en la interpretación de textos periodísticos. Defendemos, en este sentido, el rigor de la fuente, ya que partimos de la idea que la prensa tiene un indiscutible papel de concienciación social, si interpretamos de forma consciente y analítica, tanto sus afirmaciones como sus silencios, tan habituales y significativos en épocas dictatoriales. Es obvio, pero, que resulta absolutamente necesario analizar la prensa en su contexto político y social. Y, por tanto, es ineludible valorar e interpretar todos los factores que la hacen posible y los que conviven con ella: factores de tipo cultural, político o económico.

Ciertamente, hemos utilizado otras fuentes documentales que nos han ayudado a aproximarnos a un mayor conocimiento del contexto histórico. Informaciones recogidas de información oficial y privada. Complementar informaciones periodísticas con otras fuentes nos ha permitido valorar en su justa medida las noticias y opiniones que extraídas de los periódicos. Sólo así, es lícito emplear la prensa como medio de estudio.

Así pues, la investigación se ha sustentado, en buena medida, además de la bibliografía citada, y fuentes hemerográficas procedentes de Girona y su provincia, de Barcelona, de Madrid y de París, en fuentes archivísticas tales como: Archivo Histórico Nacional de Madrid, Archivo General Militar de Segovia, Biblioteca de Catalunya de Barcelona, Institut Municipal d'Història de Barcelona, Archivo Histórico de Girona (Fondo de la Administración Central Delegada). También se ha utilizado para la investigación fuentes personales (especialmente de la saga de periodistas gerundenses Masó).

\section{La censura. Instrumento de coacción y control}

La censura fue la protagonista estelar del régimen de Primo de Rivera. No podríamos entender el funcionamiento de la Dictadura sin conocer el lamentable peso específico que dispone, en esta época, la censura. El periodista madrileño Rafael Marquina niega el tópico según el cual, durante la Dictadura y gracias a la censura, la prensa ganó en sutileza, ingenio, amenidad y "extensión", dado que los periodistas necesitaban un gran esfuerzo mental y la utilización de infinidad de ingeniosos artificios para poder publicar y expresar, a menudo de manera implícita, las ideas y opiniones, los cuales necesitaban, también, una capacidad complementaria para poder escribir sobre cualquier tema frívolo y divertido que llenara páginas y entretuviera al lector. ${ }^{5}$

Sin duda, el lector tuvo que aprender a leer, a veces, entre líneas. Los periodistas, desconcertados por la censura, a falta de otros temas y ante la necesidad de llenar las páginas de sus periódicos, debían prestar atención a temáticas que, con toda seguridad y en una coyuntura de normalidad, habría pasado mucho más desapercibida. A pesar

5 Prólogo de R. Marquina al libro: DE LA IGLESIA (1930): 13 y 19. 
de la aparente contradicción, el contexto para la prensa era francamente positivo: descenso de la analfabetización, importantes avances tecnológicos en el ámbito de la impresión y la circulación de las noticias, pero las restricciones informativas impuestas por la censura y el control significaron un lastre de enormes consecuencias 6 .

La organización de la censura guarda alguna equivalencia con la organización piramidal de las instituciones del régimen. En Madrid fue creada la Oficina de Información y Censura, dirigida inicialmente por Pedro Rico Parada. Posteriormente, Rico fue nombrado director del periódico oficialista La Nación y asumió, entonces -en el año 1925-, el cargo de jefe de censura el teniente coronel Celedonio de la Iglesia, que lo aceptó con poca ilusión, pero como si se tratara de cualquier otro destino militar. Aunque la diversificación territorial en el ejercicio de la censura era absoluta y, por tanto, siempre supeditada a los subjetivos criterios del censor correspondiente, la Oficina de Información y Censura de Madrid representa un punto de referencia importante, y su tarea es orientativa en la aplicación de la política de censura.

Al centralizar la censura en torno a la Presidencia, se podía controlar con más precisión su desarrollo. Se recibían recomendaciones de Primo de Rivera en el sentido de orientar, en determinados momentos, el rigor de la censura. En provincias, la delegación de la censura correspondía a los gobernadores civiles, que, si bien estaban sometidos a los grandes criterios emanados de Madrid, gozaban de una autonomía notable. Las diversas delegaciones del gobernador a los alcaldes u otros cargos gubernativos para ejercer la censura imposibilitaba, aún más, una unidad de criterios. Esto podía provocar mayores arbitrariedades de las que por definición ya originaba el simple ejercicio de la censura. Sin embargo, las influencias y divergencias personales incrementaban la injusticia.

La implicación de varios personajes en la aplicación de la censura originaba, incluso, un cierto confusionismo entre las mismas autoridades y la prensa, hasta el punto que uno podía llegar a desconocer dónde había que llevar las galeradas. Para intentar resolver este problema, en julio de 1925 se anunciaba que en los pueblos los delegados gubernativos no debían intervenir en la censura y, en cambio, había que entregar los originales al alcalde. Así, la estructura organizativa de la censura lejos de Madrid presentaba un aspecto poco consistente y sólida, con grietas -aprovechadas en ocasiones por los periodistas-, lo que denota improvisación, a pesar de la gran importancia que otorga Primo de Rivera a la prensa para la consolidación de su política. Estas deficiencias afectan, incluso, una capital de la magnitud de Barcelona. En este sentido es muy significativo el telegrama que el gobernador civil de Barcelona envía al ministro de Gobernación el día 28 de julio de 1927 :

"Por hallarse la censura muy escasa de personal en estos días, pues el Jefe de la misma, que es el oficial Mayor de este Gobierno está desempeñando la Secretaria, y otro de los censores ha enfermado, no se dio cuenta de la insidia que para el Ejército envolvía la caricatura que publicó L'ESQUELLA DE LA TORRATXA en la página 473 del número correspondiente al día 22 del actual, pero al repasar la Prensa advertí

6 GONZÁLEZ CALLEJA (2005): 285-291. 
tal ofensa y por ello acordé inmediatamente la imposición de una multa de 1000 pesetas"'.

Así pues, si por falta de personal o por descuido del censor, un periódico incluía una noticia susceptible de ser censurada, recaía en el mismo periódico toda la culpabilidad y, por tanto, era censurado. Se trataba de una nueva arbitrariedad, dentro la arbitrariedad que ya representaba el hecho de la existencia de la propia censura.

En relación a los temas censurables, el elenco era considerable, aunque destacan los referentes a Marruecos y a Cataluña, aunque las informaciones internacionales era también un foco de atención y preocupación para los censores. Bajo el tamiz de la censura, se puede vislumbrar la tendencia de la diplomacia española, pues las noticias que se producían en otros estados debían recibir, según el gobierno español, un tratamiento muy particular y cuidadoso, sobre todo si hacían referencia a Estados amigos. Este es el caso del fascismo, que no podía ser objeto de críticas desfavorables.

Portugal era un Estado que disponía, también, de la protección del gobierno español, el cual a través de su ministro de Gobernación exigía a todos los gobernadores civiles que velaran por el buen nombre de aquel régimen:

\footnotetext{
“Algunos periódicos de provincias vienen publicando estos días artículos tendenciosos y contrarios al régimen político de Portugal, inspirados según parece por la Agencia llamada Spania y como no deben consentirse campañas de esta índole contra el Gobierno de una Nación amiga, encargo a V.E. cuide muy especialmente de que la Prensa de esa capital y pueblos provincia se abstenga de publicar artículos o noticias que puedan perjudicar al régimen de gobierno en Portugal"s.
}

El caso contrario se producía con los regímenes opuestos al español, como era el bolchevique en la Unión Soviética: estaba absolutamente prohibido su enaltecimiento. En consecuencia, eran publicados escritos tendenciosos, con el único objetivo de desacreditar aquellas repúblicas; a menudo el articulista firmaba su escrito en la Unión Soviética cuando, en realidad, ni siquiera había estado nunca. Del mismo modo que actualmente no se puede reconstruir la situación marroquí a partir de las páginas de los periódicos de aquella época, es también absolutamente imposible analizar, con una base mínimamente objetiva y real, la situación soviética tomando como instrumento de estudio la prensa editada en España.

Un tema especialmente polémico y controvertido fue el de las persecuciones religiosas en México. El gobierno español quiso satisfacer, por un lado, la religión católica y, por otro, el gobierno mexicano. Esta imposible dicotomía hizo muy difícil el papel de la censura, ya que había que buscar un difícil punto de equilibrio, más o menos satisfactorio para ambas partes. Normalmente, se tendió a autorizar las informaciones de la represión sobre el clero mexicano, y los periódicos denunciaban, en consecuencia, la política del general Calles. Una editorial publicada por el Diario de

7 Archivo Histórico Nacional. Madrid. Sección "Directorio. Gobernación”. Serie 49-A.

8 Archivo Histórico Nacional. Madrid. Sección "Directorio. Gobernación”. Serie 49-A. Fecha: 25-21927. 
Gerona, el 5 de agosto de 1926, bajo el título de "Momento crítico", resulta altamente emblemática: "Los preceptos constitucionales que ahora por primera vez van a traducirse en una realidad de hecho en la república mejicana, constituyen una violación no sólo de los derechos de la Iglesia Católica, sino además de la ley natural y del mismo derecho de gentes".

El interés por mantener unas excelentes relaciones con EE.UU. hizo que el gobierno español prohibiera, a principios de agosto de 1927, toda referencia al caso de Sacco y Vanzetti. La prohibición supuso que la prensa española no pudiera participar en la gran ola de indignación internacional que provocó la ejecución de Sacco y Vanzetti $\mathrm{y}$, por tanto, la noticia pasó muy desapercibida en Cataluña y en el resto de España.

\section{La imagen de los despropósitos}

Con los nuevos esquemas estructurales y de contenido de la prensa, asociados a la ascensión de una nueva sociedad, la imagen que percibía el lector del diario era fundamental. La modernidad imponía una compaginación periodística diferente, donde primaba el aspecto gráfico. Los efectos tangibles y materiales provocados por el ejercicio de la censura -si es que había llevado el periódico a la censura una vez compaginado- era la antítesis del nuevo concepto de prensa: grandes manchas negras o espacios blancos, en definitiva, constataciones evidentes del paso de la censura. La prensa, a veces de manera consciente y voluntaria pretendía exagerar esta circunstancia, como reacción de queja o bien, simplemente, para cubrir espacios donde había desaparecido el texto. El Directorio conocía estos procedimientos y se empeñó en evitarlos: en noviembre de 1923 prohibía la publicación de espacios en blanco o puntos suspensivos, sustitutorios de las noticias o párrafos eliminados por la censura.

A veces los periódicos procuraban paliar los efectos visuales de la censura con estrategas menos comprometedoras, como la de tapar los espacios en blanco con la publicidad, con lo que los anuncios no mantenían la ubicación en el periódico que habían pactado los anunciantes; esto podía provocar quejas de éstos, como en el caso de La Voz de Soria cuando, el 15 de septiembre de 1925, debe justificar dichas modificaciones: "Contestando a las cartas que recibimos de nuestros anunciantes, les hacemos presente que el cambio de lugar de sus anuncios en las planas de nuestro periódico obedece a tener que utilizarlos para sustituir otros originales. Causas ajenas a nuestra voluntad nos obligan a ello" .

En ocasiones, las soluciones adoptadas por los diarios eran menos cuidadosas y podían irritar a las autoridades. En la portada del Diario de Gerona, correspondiente al día 14 de enero de 1926, junto con un esponjado editorial, se insertó por triplicado la leyenda "Este número ha pasado por la censura gubernativa", que se repetía en el interior. Este atrevimiento, le valió una sanción que, según el escrito del Gobierno

9 PÉREZ ROMERO (1983): 117. 
Civil firmado por Prudencio Rodríguez Chamorro el 15 de enero -y publicado en la prensa cuatro días más tarde-, se fundamentaba en:

“Apareciendo en el número 10 del periódico de su digna dirección correspondiente al día 14 de los corrientes, en tres sitios distintos en la primera cara y uno en la cuarta, que el mismo ha sido sometido a la previa censura del Gobierno civil, con lo que trata de disimular claros en dicho periódico lo cual está reiteradamente prohibido, y estimando que su proceder en tal sentido constituye una premeditada y por lo tanto grave desobediencia a las órdenes que sobre ello se tienen dictadas, con esta fecha he acordado corregir gubernativamente dicha desobediencia imponiéndole la multa de doscientas cincuenta pesetas que deberá hacer efectiva en papel de pagos al Estado correspondiente en el plazo de diez días, durante cuyo plazo puede recurrir en alzada ante el Excmo. Sr. Ministro de la Gobernación, previo depósito del importe de la multa".

El Diario de Gerona decidió dirigirse directamente al gobernador civil, y le expusieron las oportunas explicaciones, las cuales, al parecer, le convencieron, ya que fue condonada la multa. El Diario de Gerona había introducido un nuevo elemento que delataba el paso de la censura. En todo caso, el gobierno no pudo extirpar las indiscretas manchas -blancas o negras, no importa-, y de esta manera se continuaron publicando los periódicos, incapaces de reaccionar en cuestión de muy pocas horas con una nueva propuesta de compaginación, ante una fulminante acometida de la censura.

A pesar de los esfuerzos del gobierno, la huella que dejaba la censura en las páginas de los periódicos delataba los métodos represivos que se ejercía y la mínima libertad de expresión existente. En 1924 marca el cenit del rigor, y los ilustrativos espacios en blanco o todo en negro son la muestra más indiscutible.

La censura no se ejercía de manera uniforme entre todas las publicaciones. Lógicamente, había una mayor predisposición a censurar un determinado tipo de prensa, pero a veces se incurría en la contradicción de autorizar una noticia en un periódico y prohibirla en otro, sin ningún motivo aparente que lo justificara. Cuando el régimen crea su periódico oficial La Nación, se agudiza la falta de criterio censor. Como dice Celedonio de la Iglesia:

"Noticias que se estaban tachando a toda la Prensa de la tarde venían a última hora en galeradas de La Nación, al mismo tiempo que ésta se estaba ya tirando, y a pesar de las desesperadas llamadas por teléfono de los censores a los periódicos para autorizarlas, con espíritu de equidad que jamás falto al personal, no llegaban a tiempo estas indicaciones, para evitar una enojosa desigualdad, y en todo caso producían una gran perturbación" "10.

Estas desigualdades informativas entre periódicos podían crear situaciones comprometidas a los gobernadores cuando comprobaban, en ocasiones, que determinada prensa de Madrid publicaba una noticia prohibida a la prensa del resto del Estado,

10 DE LA IGLESIA (1930): .52-53. 
originándose agravios comparativos. Un caso generado en torno al Ayuntamiento de Barcelona puede ilustrar la desazón del gobernador civil de la capital catalana:

"Tribunal Contencioso Administrativo ha dictado sentencia anulando concurso hecho por Ayuntamiento para nombrar unos médicos municipales, asunto que ha dado lugar a una larga campaña de Prensa y de los interesados para que prosperara su reclamación. Durante estancia Sr. Presidente en Barcelona ordené que no se permitiese publicación noticia en Prensa y así se ha hecho, habiendo salido una vez en $\mathrm{La}$ Publicitat por descuido censor a quién he separado del cargo y otra en mismo periódico sin haberla traído a censura, por lo que impondré debida sanción. Pero como quiera que noticia la ha insertado $A B C$ y los interesados intentarán seguramente que salga ruego a VE me diga si sería oportuno autorizar la publicación"ll.

A veces, tampoco quedaba claro quién era el responsable de la publicación de algún escrito sujeto a la censura. Así, vemos como, a finales del mes de abril de 1927, el gobernador civil de Barcelona multa con 250 pesetas la compañía Energía Eléctrica Catalana, por haber publicado en la prensa de Barcelona un artículo que había sido anteriormente insertado en la prensa de Girona, pero parcialmente censurado. El artículo en cuestión hacía referencia a un pleito que tenía la Energía Eléctrica con el Ayuntamiento de La Bisbal d'Empordà. Por lógica, las responsabilidades podían haber recaído en los periódicos que publicaron íntegramente el escrito o bien en el censor de Barcelona. En general, la falta de criterio era muy significativa.

\section{Conclusiones}

A pesar de que no funcionara el propósito de Primo de Rivera de fundamentar buena parte de su proyecto político en el desarrollo de una intensa labor propagandística, el franquismo asumió los postulados básicos que inspiraron aquellos principios; utilización de la prensa como un instrumento imprescindible para inculcar ideología. Alejandro Quiroga sostiene que la dictadura primoriverista desarrolló los principios de un nacionalismo de esencia fascista, muy español, y que llegó a constituir el pilar de la dictadura franquista ${ }^{12}$, mientras que Xavier Casals considera que los regímenes de Franco y Primo presentan algunas similitudes con el fascismo, pero su visión del mundo es mucho más cercano al corporativismo de los católicos y tradicionalistas: "Da questo punto di vista il carattere fascista del franchismo fu strettamente associato alla radicata cultura politica della destra radicale e reazionaria spagnola piuttosto che alle ideologie tedesche e italiane. E se il regime nazista, a differenza di quello italiano, mantenne un ascendente ben noto su Franco dopo la fine della Guerra civile nel 1939 (vincolato al pagamento di un debito di guerra enorme), tale ascendente si

11 Telegrama del gobernador civil de Barcelona al ministro de Gobernación de fecha 11-7-1927. Archivo Histórico Nacional. Madrid. Sección "Directorio. Gobernación ".

12 QUIROGA (2008): 6. 
attenuò notevolmente a partire dal 1942"13. Resulta incontestable que la sombra de Primo planeó sobre múltiples aspectos del franquismo ${ }^{14}$.

El análisis comparativo de la Ley de Prensa del 1938 nos permite descubrir sus similitudes con la reglamentación de prensa primoriverista. No obstante, cabe reconocer, también, las influencias que recibe de las doctrinas totalitarias imperantes en Alemania e Italia. La identificación entre Estado y prensa es coincidente entre los dos regímenes, aunque el franquismo entendía a la prensa como algo visceral al Estado, razón por la cual la Ley del 1938 no admitía la noción de "cuarto poder" referido a la prensa y manifestaba que era uno de los "viejos conceptos que el nuevo Estado había de someter más urgentemente a revisión". Así, la prensa no era ni representaba ningún poder, los poderes los tenía el Estado, y la prensa era un instrumento al servicio del Estado, una "institución nacional", un servicio público en ocasiones en manos privadas, pero en definitiva empresas que tenían que subordinar sus intereses privados, puramente mercantiles, al gran interés "nacional", servido, interpretado y definido por el Estado. La empresa privada que planteaba un modelo de "periodismo informativo" estaba regida por personajes vinculados al régimen. Con el principio expresado en la Ley del 1938, según el cual el Estado tenía funciones de "organización, vigilancia y control de la institución nacional de la Prensa Periódica", quedaba claro que la prensa servía al Estado, desapareciendo la antigua concepción industrial de la prensa en manos de empresas privadas.

Las consignas del régimen del general Franco significaron la culminación de la función que Primo de Rivera había reservado a las notas oficiosas. Sin duda, la esencia era la misma: asegurar la función manipuladora de la prensa al divulgar lo que el gobierno, como representante e intérprete del sentir "nacional" le interesaba difundir en cada momento. Primo de Rivera no supo, pero, articular de forma efectiva el sistema de las notas oficiosas y, cuando decidió reglamentar sus inserciones obligatorias en la prensa, el régimen ya estaba herido de muerte.

En definitiva, Primo de Rivera no consiguió reglamentar la prensa a fondo. Se limitó a dictar Reales Decretos y Órdenes, a medida que el tiempo transcurría, y sobre la marcha. Posiblemente, le faltó la parte ideológica más radical de los regímenes autoritarios. Consideramos que la inexistencia de una planificación político-ideológica, que acompañara el simple acto de efectuar un golpe de Estado, no le permitió estructurar el Estado ni sus órganos. Se percibía claramente una sensación de improvisación y provisionalidad, que desapareció con la legislación de prensa franquista, la cual se articuló antes de la conclusión de la Guerra Civil, en el año 1938; esto podría explicar, también, la duración de un régimen y el otro. Primo de Rivera, se conformaba con apropiarse únicamente de la función de la prensa - del cuarto poder-, permitiendo la existencia de un a prensa externa al Estado, a la cual se le exigía que estuviera al servicio de de éste, pero con unos ciertos niveles de independencia. Así

13 CASALS (2011): 58.

14 GÓMEZ-NAVARRO (2003): 14. 
pues, el franquismo recogió y superó la idea de Primo de Rivera, de utilizar la prensa al servicio del régimen (identificado siempre con el Estado).

\section{Referencias bibliográficas}

BEN-AMI, Shlomo (1983). La dictadura de Primo de Rivera 1923-1930, Barcelona: Planeta.

CASALS, Xavier (2011): "Miguel Primo de Rivera, 1'architetto del franchismo". Passato e presente. Revista di storia contemporánea, 82, p. 39-65.

CASERO, Andreu (2009): "El control político de la información periodística". RLCS, Revista Latina de Comunicación Social, 64, Universidad de La Laguna: La Laguna (Tenerife).

DE LA IGLESIA, Celedonio (1930): La censura por dentro, Madrid: Compañía Iberoamericana de Publicaciones, S.A.

FUENTES LANGAS, Jesús (1998): La dictadura de Primo de Rivera en Navarra, Gobierno de Navarra.

GARRIDO MARTÍN, Aurora (1997): La dictadura de Primo de Rivera, ¿ruptura o paréntesis? Cantabria, 1923-1931, Ayuntamiento de Santander.

GATICA COTE, Daniel (2004): Dictadura y dictablanda en el Puerto de Santa María, 1923-1931, Ayuntamiento de El Puerto de Santa María.

GÓMEZ APARICIO, P (1981): Historia del periodismo español, Madrid: Editora Nacional.

GÓMEZ-NAVARRO, J.L (1991): El Régimen de Primo de Rivera, Madrid: Ediciones Cátedra.

GÓMEZ-NAVARRO, J.L (2003): “Primo de Rivera ¿Un modelo para Franco?”. Clio, núm. 23.

GONZÁlEZ CALBET, M. Teresa (1987): La Dictadura de Primo de Rivera. El Directorio Militar, Madrid: Ed. El Arquero.

GONZÁLEZ CALLEJA, Eduardo (2005): La España de Primo de Rivera. La modernización autoritaria, Madrid: Alianza Editorial.

JIMÉNEZ MARTÍNEZ, María Dolores (2003): Favores e intereses. Política de clientelas y cultura electoral en Almería (1903-1923), Universidad de Jaén.

MARTÍNEZ GÓMEZ, Pedro (2007): La dictadura de Primo de Rivera en Almería (1923-1930). Entre el continuismo y la modernización, Universidad de Almería.

QUIROGA, Alejandro (2008): Haciendo españoles. La nacionalización de las masas en la Dictadura de Primo de Rivera (1923-1930). CEPC: Madrid.

PÉREZ ROMERO, Emilio (1983): La provincia de Soria durante la dictadura de Primo de Rivera, 1923-1930, Soria: Centro de Estudios Sorianos.

ROIG ROSICH, J.M, La Dictadura de Primo de Rivera. Un assaig de repressió cultural (1992): Barcelona, Publicacions de l'Abadia de Montserrat.

RULL, Xavier (2010): "Política i manipulació del llenguatge", Comunicació. Revista de recerca i anàlisi, núm. 27, Barcelona, Societat Catalana de Comunicació.

TARDUCHY, Emilio R (1929): Psicología del dictador. Caracteres más salientes, morales y politicos de la Dictadura española, Madrid: Sáenz Hnos. 


\section{El autor}

Lluís Costa es Doctor en Historia y Profesor Titular de la Universidad de Girona. Sus líneas de investigación han tenido como eje principal la historia de la comunicación y sus relaciones con la sociedad, así como el análisis de los lazos históricos entre Cuba y Cataluña. Es autor de más de una quincena de libros. Ha participado en diversos eventos científicos y académicos celebrados en Cuba y ha impartido docencia en la Universidad de Río Piedras en San Juan de Puerto Rico. Es el director del Grupo de Investigación "Comunicación Social e Institucional" y responsable de la organización del Campus de la Comunicación de de la Universidad de Girona. 